\title{
Impact of obesity on outcomes for patients hospitalised with pneumonia
}

\author{
Phoebe King*, Eric M. Mortensen*,\#, Mary Bollinger", Marcos I. Restrepo ${ }^{\#, \oplus,}$ \\ Laurel A. Copeland ${ }^{+}$, Mary Jo V. Pugh ${ }^{\#, \S, f}$, Brandy Nakashima*, \\ Antonio Anzueto ${ }^{\#, \bullet}$ and Polly Hitchcock Noël ${ }^{\#, * *}$
}

ABSTRACT: Obesity is an increasing problem in the USA, and research into the association between obesity and pneumonia has yielded conflicting results.

Using Department of Veterans Affairs administrative data from fiscal years 2002-2006, we examined a cohort of patients hospitalised with a discharge diagnosis of pneumonia. Body mass index was categorised as underweight $\left(<18.5 \mathrm{~kg} \cdot \mathrm{m}^{-2}\right)$, normal $\left(18.5-24.9 \mathrm{~kg} \cdot \mathrm{m}^{-2}\right.$, reference group), overweight $\left(25-29.9 \mathrm{~kg} \cdot \mathrm{m}^{-2}\right)$, obese $\left(30-39.9 \mathrm{~kg} \cdot \mathrm{m}^{-2}\right)$ and morbidly obese $\left(\geqslant 40 \mathrm{~kg} \cdot \mathrm{m}^{-2}\right)$. Our primary analyses were multi level regression models with the outcomes of 90 -day mortality, intensive care unit (ICU) admission, need for mechanical ventilation and vasopressor utilisation.

The cohort comprised 18746 subjects: $3 \%$ were underweight, 30\% were normal, $36 \%$ were overweight, $27 \%$ were obese and $4 \%$ were morbidly obese. In the regression models, after adjusting for potential confounders, morbid obesity was not associated with mortality (OR 0.96, $95 \% \mathrm{Cl} 0.72-1.28$ ), but obesity was associated with decreased mortality (OR $0.86,95 \% \mathrm{Cl} 0.74-$ 0.99). Neither obesity nor morbid obesity was associated with ICU admission, use of mechanical ventilation or vasopressor utilisation. Underweight patients had increased 90-day mortality (OR 1.40, 95\% Cl 1.14-1.73).

Although obesity is a growing health epidemic, it appears to have little impact on clinical outcomes and may reduce mortality for veterans hospitalised with pneumonia.

\section{KEYWORDS: Obesity, pneumonia}

(1) $\mathrm{n}$ the USA, pneumonia affects approximately four million individuals per year [1] and, in combination with influenza, is the eighth leading cause of death and the leading cause of infectious death [2]. Despite the major impact of pneumonia on mortality, little attention has been focused on potential contributors to pneumoniaassociated deaths [3].

Obesity is an increasing problem in the USA and globally. In 2005, the World Health Organization reported that worldwide, 1.6 billion adults were overweight and 400 million adults were obese. As the obesity epidemic grows, an estimated 2.3 billion adults will become overweight; 700 million adults will be obese by 2015 [4]. Obesity has been shown to be an independent risk factor for allcause mortality [5-8], and it has been established that obese individuals have higher rates of mortality from ischaemic heart disease, stroke, diabetes, renal disease and liver disease [9].

Obesity has been identified as a risk factor for the development of a variety of infections. The positive association between obesity and infection has been well described [10-13], and it is known that obese individuals demonstrate altered lung function [14]. When these underlying alterations in lung function are considered in combination with the increased risk of infection in this patient population, it can be hypothesised that obese patients may be more likely to develop pneumonia and be at an increased risk for morbidity and mortality. There is a surprising lack of clinical data regarding the impact of obesity on pneumonia, and the studies that have been published to date demonstrate conflicting results [15-20].

Some studies suggest that obese patients are at increased risk for the development of pneumonia [16], while others do not support that association $[15,18]$. Additionally, the relationship between obesity and mortality secondary to pneumonia is uncertain, as it appears that obesity has little clinical impact on pneumonia outcomes [19], and in several studies has been associated with reductions in mortality $[17,20]$.

The increasing prevalence of obesity in the USA, coupled with the uncertainty as to whether obese
AFFILIATIONS

${ }^{*}$ Dept of Medicine, Divisions of Hospital Medicine, University of Texas Health Science Center at San Antonio, San Antonio, TX,

${ }^{*}$ VERDICT/South Texas Veterans Health Care System, San Antonio, TX, "Dept of Pulmonary and Critical Care Medicine, University of Texas Health Science Center at San Antonio, San Antonio, TX

${ }^{+}$Central Texas Veterans Health Care System and the Center for Applied Health Research, Scott \& White Healthcare, Temple, TX,

${ }^{\S}$ Geriatrics and Gerontology, University of Texas Health Science Center at San Antonio, San Antonio, $\mathrm{TX}$,

${ }^{f}$ Dept of Epidemiology and Biostatistics, University of Texas Health Science Center at San Antonio, San Antonio, TX, and ${ }^{* *}$ Clinical Epidemiology, University of Texas Health Science Center at San Antonio, San Antonio, TX, USA.

CORRESPONDENCE

E.M. Mortensen Dallas VA Medical Center General Internal Medicine (111E) 4500 South Lancaster Dallas TX 75216 USA E-mail: Eric.Mortensen@ UTSouthwestern.edu

Received:

Oct 222011

Accepted after revision:

June 222012

First published online:

Aug 302012

Online ISSN 1399-3003 
patients are at an increased risk of adverse pneumonia-related outcomes, makes this topic an area deserving of additional research. Therefore, the aim of this study was to examine the effect of obesity on clinical outcomes for veterans hospitalised with pneumonia after adjusting for potential confounders. Our a priori hypothesis was that obesity would be associated with worse clinical outcomes for patients hospitalised with pneumonia.

\section{METHODS}

We used data from the administrative databases of the Department of Veterans Affairs health care system (VA) [21]. The Institutional Review Board of the University of Texas Health Science Center at San Antonio (San Antonio, TX, USA) approved this study.

\section{Inclusion and exclusion criteria}

Patients who had at least one outpatient clinic visit during fiscal year 2002, who were hospitalised during fiscal year 2002 through the first half of fiscal year 2009 with a previously validated discharge diagnosis of pneumonia (International Classification of Diseases, ninth revision (ICD-9) codes 480.0 483.99 or $485-487.0$ ) or a secondary discharge diagnosis of pneumonia with a primary diagnosis of respiratory failure (ICD-9 code 518.81) or sepsis (ICD-9 code 038.xx) [22], and who received at least one dose of an antibiotic within $48 \mathrm{~h}$ of admission, were included in this study.

\section{Data sources and population}

This retrospective study utilised sociodemographic, diagnostic, anthropometric, mortality, utilisation and pharmacy data. Sociodemographic data included age, sex, ethnicity and marital status. We also collected VA priority status, which consists of nine categories related to disability and income. We assigned patients to underweight (body mass index (BMI) $<18.5 \mathrm{~kg} \cdot \mathrm{m}^{-2}$ ), normal (BMI $18.5-24.9 \mathrm{~kg} \cdot \mathrm{m}^{-2}$ ), overweight (BMI 25-29.9 $\mathrm{kg} \cdot \mathrm{m}^{-2}$ ), obese (BMI $30-39.9 \mathrm{~kg} \cdot \mathrm{m}^{-2}$ ) and morbidly obese (BMI $\geqslant 40 \mathrm{~kg} \cdot \mathrm{m}^{-2}$ ), according to their baseline BMI in 2002. We assessed the presence of prior comorbid conditions by reviewing data from inpatient and outpatient administrative records using the Charlson-Deyo system [23-25].

\section{Outcomes}

Outcomes were 90-day mortality, intensive care unit (ICU) admission, use of mechanical ventilation and use of vasopressors. Mortality was assessed using the VA vital status file [26].

\section{Statistical analyses}

Categorical variables were analysed using the Chi-squared test and continuous variables were analysed using t-tests. We defined statistical significance using a two-tailed $\mathrm{p}<0.01$.

For our primary analyses, we used generalised linear mixedeffect models with the patient's hospital as a random effect. We created separate models for each of the outcomes of interest, with the patient's BMI class (normal weight as the reference group) and potential confounders as the independent variables. We included variables as covariates in the models if we hypothesised a priori that they would be associated with obesity or the outcome(s). Covariates included in the models were age, sex, marital status, race/ethnicity, count of current medications, medical and psychiatric comorbid conditions, alcohol abuse, tobacco use and drug abuse. In addition, for the outcome of 90-day mortality, we included ICU admission, use of mechanical ventilation and use of vasopressors as covariates. We examined interaction terms between age and individual BMI classes; however, since they were not statistically significant we excluded them from the final models. To analyse time-to-death for patients by weight class, we used a KaplanMeier graph to display the survivor functions.

All analyses were performed using STATA 10 (StataCorp, College Station, TX, USA) and SAS 9.2 (SAS Institute, Cary, NC, USA).

\section{RESULTS}

\section{Patient characteristics}

There were 18746 patients who met the inclusion/exclusion criteria. The mean \pm SD age was $67.5 \pm 11.9$ years, $97 \%$ were male and $54 \%$ were married. By ethnicity and race, $65 \%$ were Caucasian, 22\% were African-American, 11\% were Hispanic and $2 \%$ were of other race. When characterised according to BMI, 3\% were underweight, 30\% normal weight, 36\% overweight, $27 \%$ obese and $4 \%$ morbidly obese.

Table 1 shows the baseline patient characteristics separated by BMI categories. Statistically significant differences in chronic disease were noted between the obese and morbidly obese patients and the underweight patients. The prevalence of diabetes mellitus increased as BMI increased, with $79 \%$ of morbidly obese patients and $63 \%$ of obese patients carrying a diagnosis of diabetes mellitus, compared to $26 \%$ of normal weight and $12 \%$ of underweight patients $(p<0.0001)$. Also significant was the history of congestive heart failure (CHF), with $58 \%$ of morbidly obese and $47 \%$ of obese patients carrying a diagnosis of CHF versus $29 \%$ of normal weight patients and $19 \%$ of underweight patients $(\mathrm{p}<0.0001)$. Obese and morbidly obese patients were also more likely to have a previous myocardial infarction and chronic renal disease.

There were also statistically significant differences in chronic diseases in the normal weight and underweight populations. It is notable that $34 \%$ of underweight and $37 \%$ of normal weight patients had a prior diagnosis of malignancy versus $32 \%$ of obese and $24 \%$ of morbidly obese patients $(p<0.0001)$. The prevalence of dementia was also significant, with $10 \%$ of underweight and $9 \%$ of normal weight versus $4 \%$ of obese and $2 \%$ of morbidly obese patients having a diagnosis of dementia.

\section{Univariate outcomes}

Overall mortality at 90 days was $18 \%$. Obese and morbidly obese patients had a decreased 90-day mortality compared to underweight and normal weight patients $30 \%$ underweight, $22 \%$ normal weight, $13 \%$ obese and $11 \%$ morbidly obese; $\mathrm{p}<0.0001$ ) (table 2). Overall, $19 \%$ of patients needed ICU admission and there were no statistically significant differences in BMI categories. For the outcome of mechanical ventilation, which was used in $2 \%$ of the patients overall, there was no statistically significant difference when broken into BMI categories. Vasopressors were used in 5\% of patients, and there were no statistically significant differences in vasopressor utilisation when separated by BMI categories. 
TABLE 1 Patient characteristics by body mass index (BMI) classification

\begin{tabular}{|c|c|c|c|c|c|}
\hline Age & $69.0 \pm 3.5$ & $69.0 \pm 12.3$ & $68.5 \pm 11.7$ & $65.4 \pm 11.3$ & $59.8 \pm 10.4$ \\
\hline Male & $626(96.3)$ & $5492(97.2)$ & 6549 (97.9) & 4840 (96.6) & $703(94.7)$ \\
\hline \multicolumn{6}{|l|}{ Race } \\
\hline Hispanic & $86(13.3)$ & $677(12.0)$ & $807(12.1)$ & $445(8.9)$ & $43(5.8)$ \\
\hline Other/unknown & $7(1.1)$ & $75(1.3)$ & $144(2.2)$ & $78(1.6)$ & $8(1.1)$ \\
\hline Married & $284(43.7)$ & $2824(50.0)$ & $3792(56.7)$ & $2858(57.0)$ & $392(52.8)$ \\
\hline \multicolumn{6}{|l|}{ Medical comorbidities } \\
\hline Diabetes & $80(12.3)$ & $1470(26.0)$ & $2926(43.7)$ & $3160(63.1)$ & $586(79.0)$ \\
\hline Congestive heart failure & $124(19.1)$ & $1633(28.9)$ & $2442(36.5)$ & $2358(47.1)$ & $432(58.2)$ \\
\hline Cirrhosis & $16(2.5)$ & $155(2.7)$ & $210(3.1)$ & $183(3.7)$ & $20(2.7)$ \\
\hline COPD & $513(78.9)$ & $4051(71.7)$ & $4570(68.3)$ & $3600(71.8)$ & $575(77.5)$ \\
\hline Hepatic failure & $3(0.5)$ & $69(1.2)$ & $100(1.5)$ & $90(1.8)$ & $7(0.9)$ \\
\hline HIV & $5(0.8)$ & $68(1.2)$ & $49(0.7)$ & $24(0.5)$ & $2(0.3)$ \\
\hline Leukaemia & $13(2.0)$ & $170(3.0)$ & 259 (3.9) & $184(3.7)$ & $16(2.2)$ \\
\hline Myocardial infarction & $54(8.3)$ & $641(11.3)$ & $993(14.9)$ & $711(14.2)$ & $94(12.7)$ \\
\hline Perivascular disease & $148(22.8)$ & $1531(27.1)$ & $1990(29.8)$ & $1477(29.5)$ & $191(25.7)$ \\
\hline Hemiplegia/paraplegia & $13(2.0)$ & $156(2.8)$ & $179(2.7)$ & $119(2.4)$ & $14(1.9)$ \\
\hline Peptic ulcer disease & $58(8.9)$ & $496(8.8)$ & $548(8.2)$ & $352(7.0)$ & $34(4.6)$ \\
\hline Renal disease & $60(9.2)$ & $958(17.0)$ & 1577 (23.6) & $1377(27.5)$ & 202 (27.2) \\
\hline Psychotic disorders & $20(3.1)$ & $260(4.6)$ & $301(4.5)$ & $250(5.0)$ & $46(6.2)$ \\
\hline
\end{tabular}

Data are presented as $n$, mean \pm SD or $n(\%)$. COPD: chronic obstructive pulmonary disease.

\section{Multilevel regression models}

In the regression models (table 3), after adjusting for potential confounders, there was a statistically significant association with decreased mortality for obese patients (OR $0.86,95 \% \mathrm{CI}$ $0.74-0.99$ ), no association for morbidly obese patients (OR 0.96, $95 \%$ CI $0.72-1.28$ ) and an association with increased mortality in underweight patients (OR 1.4, 95\% CI 1.14-1.73). There was no association with ICU admission for obese (OR 0.98, 95\% CI 0.841.13 ) or morbidly obese patients (OR $1.00,95 \%$ CI $0.76-1.28)$.

Regarding mechanical ventilation, there was no significant association for obese and morbidly obese patients with mechanical ventilation (obese OR 0.92, 95\% CI 0.63-1.25; morbidly obese OR $1.15,95 \%$ CI $0.62-2.16$ ). In addition, there were no significant associations with vasopressor use (obese OR $1.19,95 \%$ CI $0.91-1.56$; morbidly obese OR $0.94,95 \%$ CI $0.59-1.52)$. Due to the increased prevalence of CHF, diabetes and renal disease in the obese and morbidly obese patients, and the increased prevalence of dementia in the normal and underweight patients, interaction terms between the BMI categories and the aforementioned variables were examined. No significant interactions were found, so we did not include these interaction terms in the final models.

\section{DISCUSSION}

The relationship between obesity and pneumonia has recently become a subject of more intensive research, and there is a lack of consensus regarding the impact of obesity on the development of and outcomes after pneumonia. Despite our hypothesis that obese patients hospitalised with pneumonia would have worse clinical outcomes, we found that after adjusting for potential confounders, obese patients actually had a lower 90day mortality rate. Additionally, morbidly obese patients did 
TABLE 2 Clinical outcomes by body mass index (BMI) classification

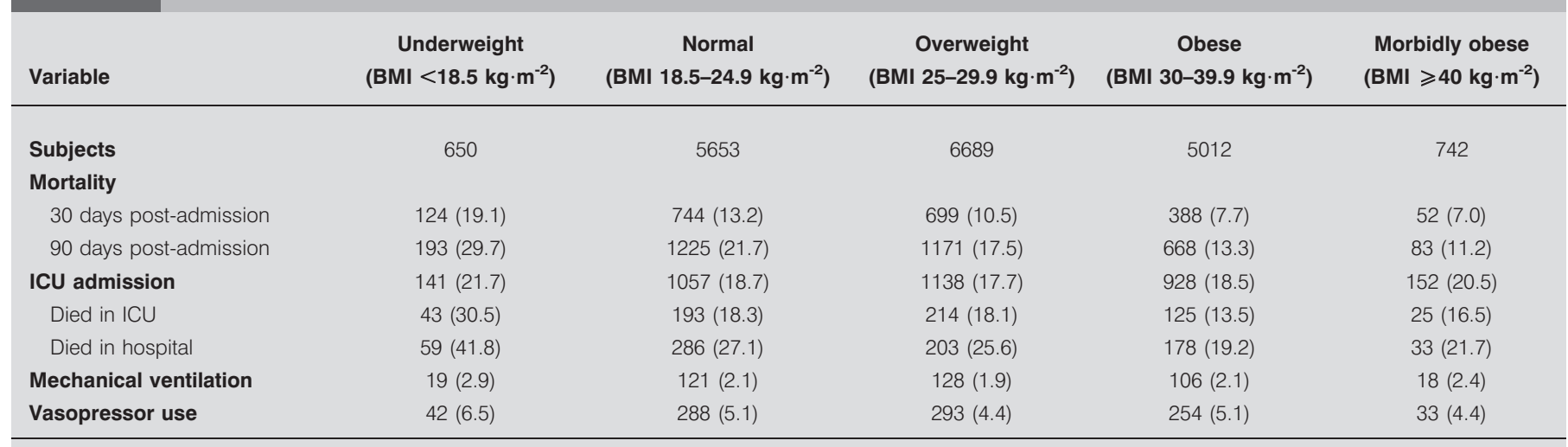

Data are presented as $\mathrm{n}$ or $\mathrm{n}(\%)$. ICU: intensive care unit.

not show an increase or decrease in mortality, and underweight patients demonstrated an increase in 90-day mortality. We did not discover any significant associations with regards to ICU admission, mechanical ventilation and vasopressor use in either obese or morbidly obese patients.

Unlike the conflicting results regarding obesity and pneumonia, a clear relationship between obesity and an increased risk of infection has been well described [10]. Obese individuals are at risk for a variety of infections, including bacteraemia, catheter-related infections [11], surgical site infections [12], poor wound healing and nosocomial infections [13]. Recent studies examining the epidemiological data regarding the recent H1N1 outbreak have also linked obesity to increased incidence of infection [27], increased mortality [28], severity of infection with the H1N1 virus and increased likelihood of requiring ICU admission [29]. Obese individuals have also demonstrated changes in underlying immune function, with alterations in lymphocyte and monocyte function resulting in a relative immunodeficient state, which leads to increased susceptibility to bacterial and viral infections [30].

The relationship between obesity and chronic respiratory diseases, such as obstructive sleep apnoea and obesity hypoventilation syndrome, has also been well described [31]. Obese individuals demonstrate altered lung function, including diminished lung volumes, decreased respiratory compliance, reduction in gas exchange, impaired respiratory muscle function and an increase in airway resistance [14]. Given this demonstrated increased risk of infection to both bacterial and viral pathogens and the underlying alterations in lung function, it is logical to theorise that obese patients would be at increased risk for both the development of pneumonia and for worse clinical outcomes. However, the relationship between obesity and pneumonia has yet to be clearly defined. Results from several previous studies concerning the relationship between obesity, pneumonia and mortality have yielded intriguing results. It would be intuitive to assume that obese patients would be more likely to have adverse clinical outcomes and increased mortality secondary to pneumonia; however, the clinical data that is currently available has not supported this hypothesis. The first of such studies performed by LACROIX et al. [19] is a prospective study examining the effect of chronic conditions, nutritional status and health behaviours on pneumonia mortality. They found that patients with low BMIs had higher pneumonia mortality compared to those with high BMIs.

More recent data on the relationship between obesity and pneumonia mortality supports our findings of the association between obesity and decreased mortality. INOUE et al. [20] performed a systematic review to ascertain the risk and protective factors of obesity for pneumonia mortality. As in our study, they found that obese patients had a reduction in pneumonia mortality compared to normal-weight patients (OR $0.7,95 \%$ CI 0.5-0.8), which was maintained after adjusting for age and the presence of diabetes. A retrospective study by CORRALES-MEDINA et al. [17] corresponds to this data, showing that in patients with proven bacterial pneumonia, obesity was associated with decreased 30-day mortality, which was again

TABLE 3 Multilevel regression analyses of clinical outcomes by body mass index (BMI) classification

\begin{tabular}{|c|c|c|c|c|}
\hline Underweight (BMI $<18.5 \mathrm{~kg} \cdot \mathrm{m}^{-2}$ ) & $1.40(1.14-1.73)$ & $1.17(0.92-1.48)$ & $1.22(0.70-2.13)$ & $1.30(0.86-1.96)$ \\
\hline Obese (BMI 30-39.9 $\mathrm{kg} \cdot \mathrm{m}^{-2}$ ) & $0.86(0.74-0.99)$ & $0.98(0.84-1.13)$ & $0.92(0.63-1.35)$ & $1.19(0.91-1.56)$ \\
\hline Morbidly obese $\left(B M I \geqslant 40 \mathrm{~kg} \cdot \mathrm{m}^{-2}\right)$ & $0.96(0.72-1.28)$ & $1.00(0.79-1.28)$ & $1.16(0.62-2.16)$ & $0.95(0.59-1.50)$ \\
\hline
\end{tabular}

Data are presented as OR $(95 \% \mathrm{Cl})$. ICU: intensive care unit. 
maintained in multivariable analysis (OR 0.88, 95\% CI $0.81-$ 0.96). Our study adds to this growing body of evidence and points toward an underlying factor that obese patients have, which affords them protection against adverse outcomes secondary to pneumonia.

One of the reasons for this possible protective effect against pneumonia may be due to an altered inflammatory response in the lung tissue of obese patients. Prior studies have shown that increasingly elevated inflammatory cytokine levels are associated with increased mortality from acute lung injury and acute respiratory distress syndrome (ARDS) [32-35]. It has also been shown that baseline inflammatory cytokine levels increase in proportion to BMI, particularly interleukin (IL)-6 and IL-8 [36-38]. STAPLETON et al. [39] examined this relationship in a retrospective study of 1409 participants in the National Heart, Lung and Blood Institute ARDS trials. Plasma levels of IL-6, IL-8, tumour necrosis factor- $\alpha$ receptor 1 , surfactant protein (SP)-D soluble intracellular adhesion molecule, von Willebrand factor (vWF), protein $\mathrm{C}$ and plasminogen activator inhibitor-1 were all measured at baseline and on hospital day 3 , and then these levels were correlated with BMI. It was found that IL-6, IL-8 and SP-D were inversely related to BMI, while vWF increased proportionally with BMI. The inversely related IL-6, IL-8 and SP-D levels suggest that obese patients may have an attenuated response to inflammation and less alveolar epithelial injury during infection, which could help protect against further lung injury, increased mortality and use of mechanical ventilation. Furthermore, given that this patient population has an already elevated level of inflammatory markers at baseline, the relative increase in inflammation would be smaller than patients of normal BMI, which also could lessen alveolar injury and potentially help explain our findings.

Another possible explanation could be related to differences in the immunological function of obese patients. Studies have demonstrated that obese individuals have increased serum levels of leptin, a protein hormone produced by adipocytes that participates in the function of both innate and adaptive immunity [40]. Leptin has been shown to increase macrophagic activity, neutrophil chemotaxis, cytotoxicity of natural killer cells and T-cell and B-cell lymphopoeisis, all of which helps to promote bacterial clearance [41]. Therefore, it could be postulated that increased leptin levels could help to enhance the immune response of obese individuals and perhaps serve in a protective role against infection. Both the role of inflammation and the immunological effects of obesity are intriguing areas of study and deserve further research to fully understand their clinical impact.

While the aim of this study was to examine the relationship between obesity and pneumonia outcomes, in congruence with prior studies [19, 20,42,43], our study also found that underweight patients had an increase in 90-day mortality, ICU mortality and in-hospital mortality after ICU admission. This could be secondary to unaccounted effects of the underlying diseases (malignancy, dementia and AIDS) that are more prevalent in the underweight patient population. Such effects may include malnutrition or an immunocompromised state, which would increase their risk for infection or mortality after illness.
There are several limitations of our study. This study consisted of patients hospitalised at VA medical centres, and therefore the results may not be directly applicable to other patient populations. Another limitation is that, due to the high prevalence of males in the VA healthcare system, $97 \%$ of the patients included in this study were male; thus, it is unclear whether the same results would have been obtained if our study population had a male to female ratio more representative of the general population. Also, the inclusion criteria for our study relied on the use of a primary or secondary discharge diagnosis of pneumonia and most diagnoses were probably obtained radiographically. This raises the possibility of overdiagnosis of pneumonia in obese and morbidly obese patients due to body habitus and poor visualisation of lung fields, which could also explain why obese patients seemed to have better clinical outcomes. Finally, due to the data source, we were unable to examine pathogens or adjust for severity of illness at presentation. It is possible that obese patients present earlier to the hospital due to "breathlessness", and this is the reason for our findings.

In conclusion, although obesity is a rapidly growing healthcare crisis and obese patients provide healthcare teams with unique challenges, they do not appear to be at increased risk for adverse clinical outcomes after hospitalisation with pneumonia. Despite the negative ramifications that are associated with obesity, our study has shown that it may actually provide a protective effect against increased pneumonia mortality. The reasons behind these results are unclear and further investigation into the exact relationship between pneumonia and obesity, and the possible mechanisms behind its protective effect, is warranted to fully understand and appreciate how obesity affects the severity and mortality of patients admitted for pneumonia.

\section{SUPPORT STATEMENT}

The project described was supported by Veterans Affairs Health Services Research and Development Service grant IIR 05-121. This material is the result of work supported with resources and the use of facilities at the South Texas Veterans Health Care System. The views expressed in this article are those of the authors and do not necessarily reflect the position or policy of the Department of Veterans Affairs or the United States government.

\section{STATEMENT OF INTEREST}

None declared.

\section{REFERENCES}

1 Bartlett JG, Mundy LM. Community-acquired pneumonia. N Engl J Med 1995; 333: 1618-1624.

2 Kung HC, Hoyert DL, Xu JQ, et al. Deaths: Final Data for 2005. Hyattsville, National Center for Health Statistics, 2008.

3 Mortensen EM, Coley CM, Singer DE, et al. Causes of death for patients with community-acquired pneumonia: results from the Pneumonia Patient Outcomes Research Team cohort study. Arch Intern Med 2002; 162: 1059-1064.

4 World Health Organization. Obesity and Overweight. Fact Sheet No. 311. May 2012. www.who.int/mediacentre/factsheets/fs311/ en/index.html Date last accessed: June 6, 2012.

5 Berrington de Gonzalez A, Hartge P, Cerhan JR, et al. Body-mass index and mortality among 1.46 million white adults. N Engl J Med 2010; 363: 2211-2219. 
6 Flegal KM, Graubard BI, Williamson DF, et al. Excess deaths associated with underweight, overweight, and obesity. JAMA 2005; 293: 1861-1867.

7 Calle EE, Thun MJ, Petrelli JM, et al. Body-mass index and mortality in a prospective cohort of US adults. N Engl J Med 1999; 341: 1097-1105.

8 Adams KF, Schatzkin A, Harris TB, et al. Overweight, obesity, and mortality in a large prospective cohort of persons 50 to 71 years old. N Engl J Med 2006; 355: 763-778.

9 Whitlock G, Lewington S, Sherliker P, et al. Body-mass index and cause-specific mortality in 900000 adults: collaborative analyses of 57 prospective studies. Lancet 2009; 373: 1083-1096.

10 Falagas ME, Kompoti M. Obesity and infection. Lancet Infect Dis 2006; 6: 438-446.

11 Dossett LA, Dageforde LA, Swenson BR, et al. Obesity and sitespecific nosocomial infection risk in the intensive care unit. Surg Infect 2009; 10: 137-142.

12 Anaya DA, Dellinger EP. The obese surgical patient: a susceptible host for infection. Surg Infect 2006; 7: 473-480.

13 Doyle SL, Lysaght J, Reynolds JV. Obesity and post-operative complications in patients undergoing non-bariatric surgery. Obes Rev 2010; 11: 875-886.

14 Murugan AT, Sharma G. Obesity and respiratory diseases. Chron Respir Dis 2008; 5: 233-242.

15 Almirall J, Bolibar I, Serra-Prat M, et al. New evidence of risk factors for community-acquired pneumonia: a population-based study. Eur Respir J 2008; 31: 1274-1284.

16 Baik I, Curhan GC, Rimm EB, et al. A prospective study of age and lifestyle factors in relation to community-acquired pneumonia in US men and women. Arch Intern Med 2000; 160: 3082-3088.

17 Corrales-Medina VF, Valayam J, Serpa JA, et al. The obesity paradox in community-acquired bacterial pneumonia. Int J Infect Dis 2011; 15: e54-e57.

18 Schnoor $\mathrm{M}$, Klante $\mathrm{T}$, Beckmann $\mathrm{M}$, et al. Risk factors for community-acquired pneumonia in German adults: the impact of children in the household. Epidemiol Infect 2007; 135: 1389-1397.

19 Lacroix AZ, Lipson S, Miles T, et al. Prospective study of pneumonia hospitalizations and mortality of US older people: the role of chronic conditions, health behaviors, and nutritional status. Public Health Rep 1989; 104: 350-359.

20 Inoue $\mathrm{Y}, \mathrm{Koizumi} \mathrm{A}, \mathrm{Wada} \mathrm{Y}$, et al. Risk and protective factors related to mortality from pneumonia among middle aged and elderly community residents: the JACC Study. J Epidemiol 2007; 17: 194-202.

21 Brown SH, Lincoln MJ, Groen PJ, et al. VistA - US Department of Veterans Affairs national-scale HIS. Int J Med Inform 2003; 69: 135-156.

22 Meehan TP, Fine MJ, Krumholz HM, et al. Quality of care, process, and outcomes in elderly patients with pneumonia. JAMA 1997; 278: 2080-2084.

23 Deyo RA, Cherkin DC, Ciol MA. Adapting a clinical comorbidity index for use with ICD-9-CM administrative databases. J Clin Epidemiol 1992; 45: 613-619.
24 Southern DA, Quan H, Ghali WA. Comparison of the Elixhauser and Charlson/Deyo methods of comorbidity measurement in administrative data. Med Care 2004; 42: 355-360.

25 Charlson M, Szatrowski TP, Peterson J, et al. Validation of a combined comorbidity index. J Clin Epidemiol 1994; 47: 1245-1251.

26 Sohn MW, Arnold N, Maynard C, et al. Accuracy and completeness of mortality data in the Department of Veterans Affairs. Popul Health Metr 2006; 4: 2-12.

27 Rothberg MB, Haessler SD. Complications of seasonal and pandemic influenza. Crit Care Med 2010; 38: e91-e97.

28 Cui $\mathrm{W}$, Zhao $\mathrm{H}, \mathrm{Lu} \mathrm{X}$, et al. Factors associated with death in hospitalized pneumonia patients with 2009 H1N1 influenza in Shenyang, China. BMC Infect Dis 2010; 10: 145.

29 Viasus D, Paño-Pardo JR, Pachón J, et al. Factors associated with severe disease in hospitalized adults with pandemic (H1N1) 2009 in Spain. Clin Microbiol Infect 2011; 17: 738-746.

30 Karlsson EA, Beck MA. The burden of obesity on infectious disease. Exp Biol Med 2010; 235: 1412-1424.

31 Piper AJ, Grunstein RR. Obesity hypoventilation syndrome: mechanisms and management. Am J Respir Crit Care Med 2011; 183: 292-298.

32 Parsons PE, Eisner MD, Thompson BT, et al. Lower tidal volume ventilation and plasma cytokine markers of inflammation in patients with acute lung injury. Crit Care Med 2005; 33: 1-6.

33 Ware LB, Matthay MA, Parsons PE, et al. Pathogenetic and prognostic significance of altered coagulation and fibrinolysis in acute lung injury/acute respiratory distress syndrome. Crit Care Med 2007; 35: 1821-1828.

34 McClintock D, Zhuo $\mathrm{H}$, Wickersham $\mathrm{N}$, et al. Biomarkers of inflammation, coagulation and fibrinolysis predict mortality in acute lung injury. Crit Care 2008; 12: R41.

35 Ware LB, Koyama T, Billheimer DD, et al. Prognostic and pathogenetic value of combining clinical and biochemical indices in patients with acute lung injury. Chest 2010; 137: 288-296.

36 Mancuso P. Obesity and lung inflammation. J Appl Physiol 2010; 108: 722-728.

37 Kim CS, Park HS, Kawada T, et al. Circulating levels of MCP-1 and IL-8 are elevated in human obese subjects and associated with obesity-related parameters. Int J Obes 2006; 30: 1347-1355.

38 Park HS, Park JY, Yu R. Relationship of obesity and visceral adiposity with serum concentrations of CRP, TNF- $\alpha$ and IL- 6 . Diabetes Res Clin Pract 2005; 69: 29-35.

39 Stapleton RD, Dixon AE, Parsons PE, et al. The association between BMI and plasma cytokine levels in patients with acute lung injury. Chest 2010; 138: 568-577.

40 Iikuni N, Lam QL, Lu L, et al. Leptin and inflammation. Curr Immunol Rev 2008; 4: 70-79.

41 Lam QL, Lu L. Role of leptin in immunity. Cell Mol Immunol 2007; 4: 1-13.

42 Almirall J, Bolibar I, Serra-Prat M, et al. New evidence of risk factors for community-acquired pneumonia: a population-based study. Eur Respir J 2008; 31: 1274-1284.

43 Schnoor $\mathrm{M}$, Klante $\mathrm{T}$, Beckmann $\mathrm{M}$, et al. Risk factors for community-acquired pneumonia in German adults: the impact of children in the household. Epidemiol Infect 2007; 135: 1389-1397. 